\title{
Analysis Method for Surface Topography Model in High Speed Milling Hardened Steel
}

\author{
Jiang Bin*, Zhang Minghui, Wang Zhigang and Guan Yancong \\ National \& Local United Engineering Laboratory of High Efficiency Cutting and Tools, Harbin University of Science \\ and Technology, Heilongjiang, Harbin, 150080, P.R. China
}

\begin{abstract}
During high speed milling hardened steel, the problem that tool vibration reducing machining surface quality causes led to a research for the influence characteristics of milled surface topography through high speed milling experiment. To determine the formation condition of milled surface topography, using displacement increment of origin of tool coordinate system which is caused by the milling cutter vibration and installation error, modifies the cutting motion trajectory. Based on the tool-workpiece contact relationship and the cutting layer parameters of contact points on two teeth, the residual units of machined surface are established, thereby proposing a solution method for the deformation and distribution characteristic of residual units under the overhanging volume and the vibration. Therefore, the milled surface topography of cutting hardness steel with high speed ball-end milling cutter is revealed to bring out a striking contrast between the simulation and experiment of milled surface topography of hardness steel.
\end{abstract}

Keywords: High speed milling cutter, Hardened steel, Tool vibration, Residual units, Milled surface topography.

\section{INTRODUCTION}

High speed ball-end milling cutter is a typical high speed milling cutter tool and widely used in finishing surface of automobile large-size hardened steel molds [1, 2]. The surface hardness of hardened steel is over HRC55, there will be larger elastic recovery and the tool vibration is under high speed milling. Therefore, this milled surface quality deterioration of hardened steel has been a key problem that mold manufacturing enterprises need to be addressed [3-5].

During the process of high speed milling complex surface of hardened steel, the uneven hardness distribution and the varied milled surface curvature change the cutting force and the cutting heat and aggravate the vibration of milling cutter and workpiece, thereby directly affecting the machined surface quality and machined efficiency. During the process of high speed milling of hardened steel mold, on the one hand, larger metal removal rate is required while reducing machine working hours. On the other hand, low vibration and high machined surface quality are required [6, 7]. There is an intense contradiction between the milling efficiency and the machined surface quality of hardened steel, hence having no access to satisfactory process schemes for high cutting efficiency and high machined surface quality of hardened steel. It is needed to conduct an in-depth research.

At present, the researches in the surface topography of high speed milling of hardened steel mold are mainly the control

\footnotetext{
*Address correspondence to this author at the School of Mechanical Engineering, Harbin University of Science and Technology, Heiliongjiang, Harbin, 150080, P.R. China; Tel: 13903611465; Fax: +86 045186390572 ; E-mail: 13903611465@163.com
}

variable method of single factor analysis, and high speed milling parameters affecting surface roughness are researched [8-10]. But the influence of the interaction between multiple features on the milled surface formation of high speed milling is not considered, and the cooperatives between cutting parameter and tool are even poor. It is difficult to get reasonable process scheme.

The existing processing methods of high speed milling hardened steel regarded machined surface roughness as design objective and established various types of machined surface roughness model to forecast and control the machined surface quality [11]. The above method cannot efficiently control the formation process of high speed milling surface which milled surface topography exist diversity and uncertainty, thereby dissatisfying requirement of high efficiency machining large precision molds.

The high speed ball-end milling cutter vibration and blade initial installation error will cause the change and offset of cutting motion trajectory, thereby directly affecting the formation process of machining surface. Aiming at the above problems existing in high speed milling of hardened steel, this paper studies the influencing characteristics of cutter vibration on the milled surface topography through an experiment of high speed milling of hardened steel with two experiment schemes, and conducts a research on the forming process of high speed milling machined surface, then establishes the simulation model of milled surface topography under the cutter vibration. Finally, the validity of the model analysis will be verified through alternative process schemes experiment. 


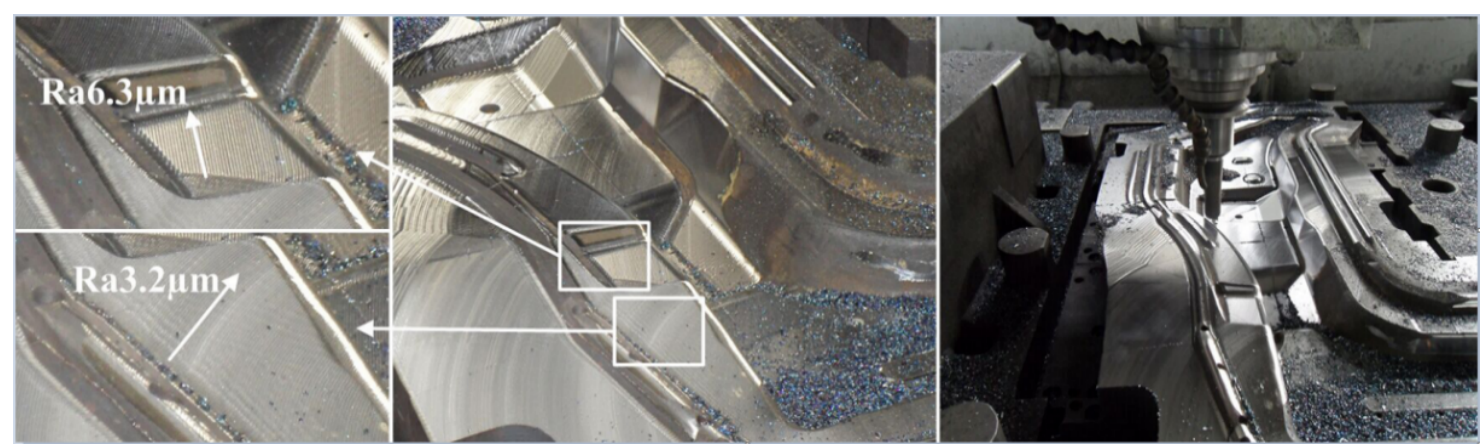

Fig. (1). Milled surface topography of hardened steel and later polishing.

Table 1. Process schemes of milling hardened steel

\begin{tabular}{|c|c|c|c|c|c|c|}
\hline Process Scheme & $\begin{array}{c}\text { Revolving Speed } \\
(\mathbf{r p m})\end{array}$ & $\begin{array}{c}\text { Feed Speed } \\
(\mathbf{m m} / \mathbf{m i n})\end{array}$ & $\begin{array}{c}\text { Row Spacing } \\
(\mathbf{m m})\end{array}$ & $\begin{array}{c}\text { Cutting Depth } \\
(\mathbf{m m})\end{array}$ & $\begin{array}{c}\text { Machined Efficiency } \\
\left(\mathbf{m m} \mathbf{m}^{\mathbf{3}} / \mathbf{m i n}\right)\end{array}$ & $\begin{array}{c}\text { Machined } \\
\text { Surface } \\
\text { Roughness } \\
(\boldsymbol{\mu m})\end{array}$ \\
\hline \hline 1 & 4000 & 3000 & 0.4 & 0.2 & 240 & $3.2 \sim 6.3$ \\
\hline 2 & 2000 & 1800 & $0.5-0.7$ & 0.1 & $90-126$ & 0.8 \\
\hline
\end{tabular}

\section{EFFECT OF HIGH SPEED MILLING CUTTER VIBRATION ON THE MILLED SURFACE TOPOGRAPHY OF HARDENED STEEL}

During the progress of machining the hardened steel mold with the high-speed ball-end mill having diameter of $20 \mathrm{~mm}$, the machined surface quality of hardened steel, the machining efficiency of process scheme and the process effect are as shown in Table $\mathbf{1}$ and Fig. (1).

As shown in Fig. (1), the process scheme with the high revolving speed and the feed speed in Table 1 can enhance the processing efficiency, but the milling cutter will be subjected to a strong vibration. Thus, the machined surface roughness will decline to $\operatorname{Ra} 3.2 \mu \mathrm{m} \sim 6.3 \mu \mathrm{m}$ which the directions of surface texture are different. This machined surface toughness will obviously increase the polishing and grinding time of machined surface of hardened steel, thereby prolonging the manufacture cycle of mold. The scheme 2 from Table 1 reduces the vibration effectively and improves the machined surface roughness reaching to $\mathrm{Ra} 0.8 \mu \mathrm{m}$. Meanwhile, this process also reduces the machining efficiency obviously. The above analysis shows that there are conflicts between the milling efficiency and the machined surface quality under the vibration.

In order to reveal the influence characteristics of milled surface topography caused by vibration, adopting the change overhanging volume conducts the experiment of milled surface topography of hardened steel under the vibration. The experiment machine is UCP710 five-axis machining center, the machining angle is $15^{\circ}$, the spindle speed is $5000 \mathrm{rpm}$, the feed of each tooth is $0.3 \mathrm{~mm}$, the row spacing is $0.3 \mathrm{~mm}$ and the cutting depth is $0.2 \mathrm{~mm}$. The workpiece material is hardness steel $\mathrm{Cr} 12 \mathrm{MoV}$ and the material hardness is HRC55 60. The experiment selects indexable ball-end milling cutter with diameter of $20 \mathrm{~mm}$ and two teeth and four overhanging volumes including $92 \mathrm{~mm}, 100 \mathrm{~mm}$,
$105 \mathrm{~mm}$ and $110 \mathrm{~mm}$. The results of the tool vibration and the milled surface topography are shown in Table $\mathbf{2}$ and Fig. (2) Fig. (5).

In Table 2, the overhanging volume increases by $18 \mathrm{~mm}$, and the natural frequency reduces by $645.6 \mathrm{~Hz}$. With the change of overhanging volume, the damping coefficient of milling cutter, the rigidity and the natural frequency appear significantly changed. Due to the decrease of the natural frequency of the cutter, the frequency of resonance region is gradually close to the exciting frequency. High frequency vibration occurs when the milling cutter overhanging volume is $100 \mathrm{~mm}$ and this high frequency becomes main frequency when the overhanging volume reaches $110 \mathrm{~mm}$. The milled surface topography changes with cutter vibration, thereby aggravating contradiction between the milling efficiency and the machined surface quality.

\section{MODIFYING CUTTING MOTION TRAJECTORY OF HIGH SPEED MILLING CUTTER}

Under the influence of the dynamic cutting force and the centrifugal force, the deflection caused by the tool vibration directly influences the cutting motion trajectory and changes the milled surface topography. Based on the position relationship among the workpiece, the milling cutter and the machine system, the machine coordinate system $\mathrm{Oj}-\mathrm{XjYjZj}$ and the tool coordinate system $\mathrm{Od}-\mathrm{XdYdZd}$ are established, the vectors along cutter feed direction and row direction are extracted, are as shown in Fig. (6) and Fig. (7).

The cutting motion trajectory equation is obtained as follows.

$$
\left\{\begin{array}{c}
x_{j}^{p} \\
y_{j}^{p} \\
z_{j}^{p}
\end{array}\right\}=\left\{\begin{array}{c}
x_{d}^{t} \\
y_{d}^{t} \\
z_{d}^{t}
\end{array}\right\}+\left\{\begin{array}{l}
x_{0}+f * \cos \lambda_{u}^{x} / 60 \cdot t+(i-1) \cdot a_{e} \cdot \cos \lambda_{v}^{x} \\
y_{0}+f^{*} \cos \lambda_{u}^{y} / 60 \cdot t+(i-1) \cdot a_{e} \cdot \cos \lambda_{v}^{y} \\
z_{0}+f^{*} \cos \lambda_{u}^{z} / 60 \cdot t+(i-1) \cdot a_{e} \cdot \cos \lambda_{v}^{z}
\end{array}\right\}
$$


Table 2. Modal parameters of high speed milling cutter.

\begin{tabular}{|c|c|c|c|}
\hline Overhanging Volume (mm) & Damping Coefficient $\left.\mathbf{( 1 0}^{-\mathbf{3}}\right)$ & $\begin{array}{c}\text { Rigidity } \\
\left(\mathbf{N} \cdot \mathbf{m}^{\mathbf{- 1}}\right)\end{array}$ & Natural Frequency $(\mathrm{Hz})$ \\
\hline \hline 92 & 1.102 & 439102 & 1752.5 \\
\hline 100 & 0.852 & 333413 & 1595.0 \\
\hline 105 & 0.816 & 310664 & 1285.8 \\
\hline 110 & 0.757 & 291802 & 1106.9 \\
\hline
\end{tabular}

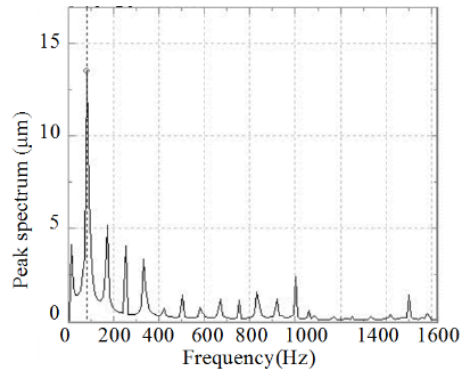

(a) Experimental results of vibration frequency domain

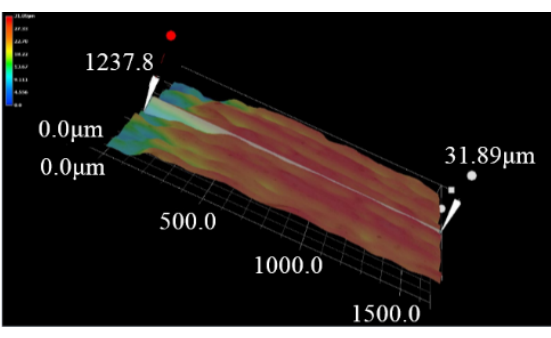

(b) Result of milled surface topography

Fig. (2). Experimental results of cutter vibration and milled surface topography when $l=92 \mathrm{~mm}$.

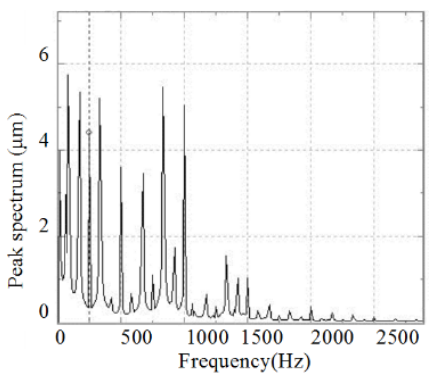

(a) Experimental results of vibration frequency domain

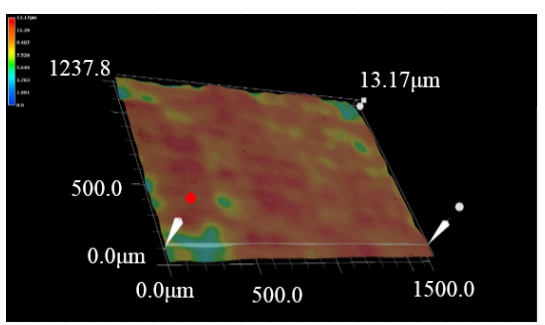

(b) Result of milled surface topography

Fig. (3). Experimental results of cutter vibration and milled surface topography when $l=100 \mathrm{~mm}$.

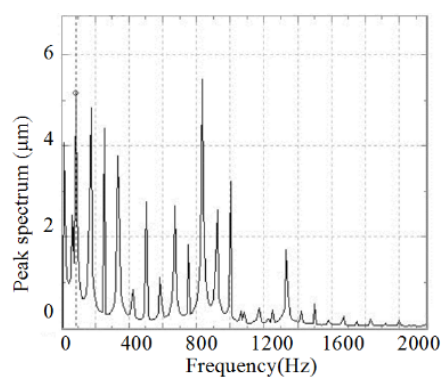

(a) Experimental results of vibration frequency domain

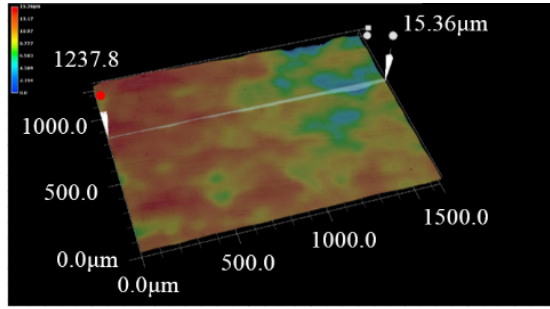

(b) Result of milled surface topography

Fig. (4). Experimental results of cutter vibration and milled surface topography when $l=105 \mathrm{~mm}$.

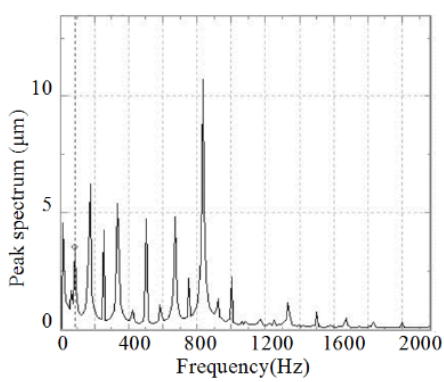

(a) Experimental results of vibration frequency domain

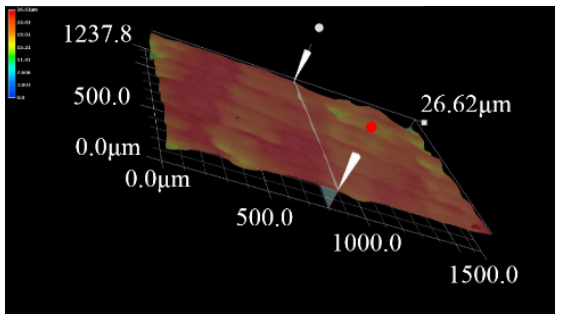

(b) Result of milled surface topography

Fig. (5). Experimental results of cutter vibration and milled surface topography when $l=110 \mathrm{~mm}$. 


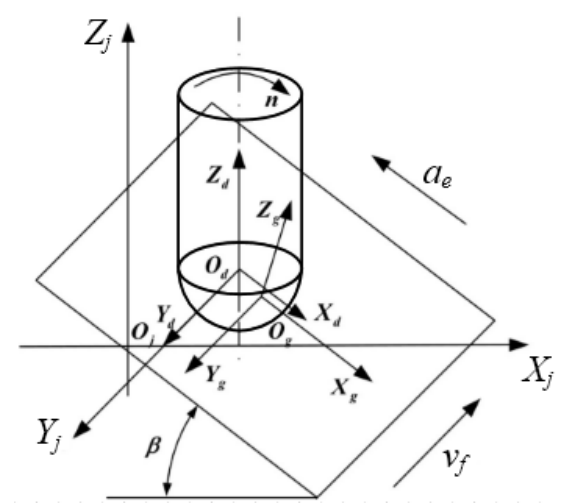

Fig. (6). Milling cutter coordinate system.

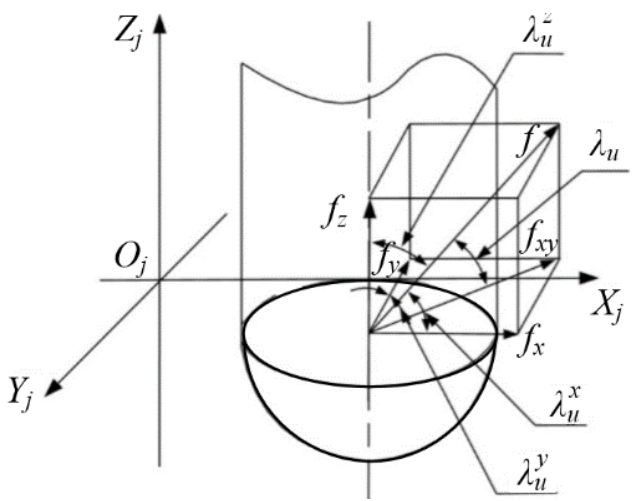

Fig. (7). Vectors along feed direction of milling cutter.

In the equation, (xpj, ypj, zpj) represents the coordinate of cutting contact point in the machine coordinate system at $t$ time. (xtd, ytd, ztd) represents coordinate of cutting contact point in the tool coordinate system at $\mathrm{t}$ time. $(\mathrm{x} 0, \mathrm{y} 0, \mathrm{z} 0)$ represents the tool origin in the machine coordinate system. $f$ is the feed. $\mathrm{i}$ are the feed times. $\lambda \mathrm{xu}, \lambda \mathrm{yu}, \lambda \mathrm{zu}$ are respectively the included angle between the feed direction and three coordinate directions of the machine coordinate system, $\lambda \mathrm{xv}, \lambda \mathrm{yv}, \lambda \mathrm{zv}$ are respectively the included angle between the row direction and three coordinate directions of the machine coordinate system.

Under the influence of vibration, the displacement increment of the tool coordinate system is

$$
\left\{\begin{array}{l}
\Delta x_{0}=\frac{ \pm \Delta d_{1} \cos \left(\Delta \alpha_{1}+\phi_{j t}-60 n t\right)}{2} \\
\Delta y_{0}=\frac{ \pm \Delta d_{1} \sin \left(\Delta \alpha_{1}+\phi_{j t}-60 n t\right)}{2} \\
\Delta z_{0}=l-\sqrt{l^{2}-\Delta d_{1}^{2}}
\end{array}\right.
$$

Where $\triangle \mathrm{d} 1$ is the radial deflection displacement of ballend milling cutter center. 1 is the overhanging volume of milling cutter. $\triangle \alpha 1$ is the initial phase angle of cutter eccentricity, which is positive when the milling cutter swings to contact points, otherwise, it is negative. jt is the angle of the $\mathrm{j}$ tooth which rotates the ball-end milling cutter from starting point on the edge to the selected point on the XOY plane at $t$ time.

Due to installation error of indexable blade, the displacement increment of the tool coordinate origin is

$$
\left\{\begin{array}{l}
\Delta x_{0}^{\prime}=\frac{ \pm \Delta d_{3} \cos \left(\Delta \alpha_{2}+\phi_{j t}-6 n t\right)}{2} \\
\Delta y_{0}^{\prime}=\frac{ \pm \Delta d_{3} \sin \left(\Delta \alpha_{2}+\phi_{j t}-6 n t\right)}{2} \\
\Delta z_{0}^{\prime}=\Delta d_{4}
\end{array}\right.
$$

Where $\Delta d_{3}$ and $\Delta d_{4}$ are respectively the radial and axial error which the blade center is relative to the ball-end milling cutter center. $\Delta \alpha_{2}$ is initial phase angle of blade eccentric, which is positive along the decentralization cutting edge joining cutting motion, otherwise, it is negative.

Using Eq. 2 and Eq. 3, the cutting motion trajectory equation of contact point is modified.

$\left\{\begin{array}{c}x_{j}^{p} \\ y_{j}^{p} \\ z_{j}^{p}\end{array}\right\}=\left\{\begin{array}{c}x_{d}^{t} \\ y_{d}^{t} \\ z_{d}^{t}\end{array}\right\}+\left\{\begin{array}{c}\Delta x_{0} \\ \Delta y_{0} \\ \Delta z_{0}\end{array}\right\}+\left\{\begin{array}{c}\Delta x_{0}^{\prime} \\ \Delta y_{0}^{\prime} \\ \Delta z_{0}^{\prime}\end{array}\right\}+$

$$
\left\{\begin{array}{c}
x_{0}+\frac{f^{*} \cos \lambda_{u}^{x}}{60} t+(i-1) * a_{e} * \cos \lambda_{v}^{x} \\
y_{0}+\frac{f^{*} \cos \lambda_{u}^{y}}{60} t+(i-1) * a_{e} * \cos \lambda_{v}^{y} \\
z_{0}+\frac{f^{*} \cos \lambda_{u}^{z}}{60} t+(i-1) * a_{e} * \cos \lambda_{v}^{z}
\end{array}\right\}
$$




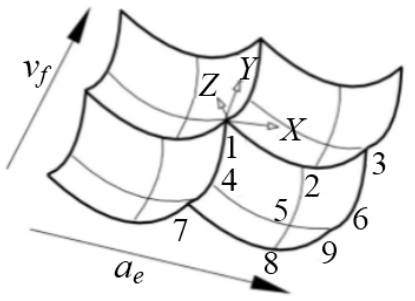

(a) Residual unit

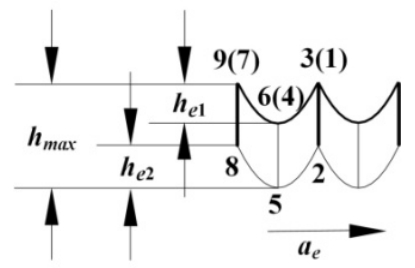

(c) Unit along row direction

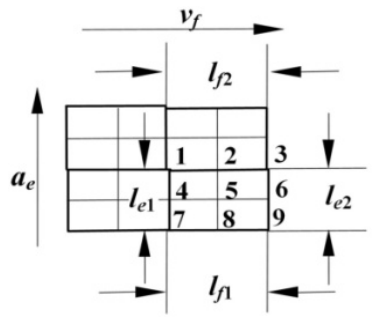

(b) Unit length

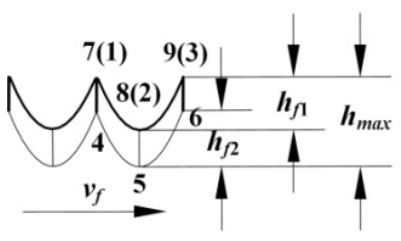

(d) Unit along feed direction

Fig. (8). Residual unit of machined surface.

Table 3. Analysis results for residual unit of machined surface

\begin{tabular}{|c|c|c|c|c|}
\hline $\boldsymbol{l}(\mathbf{m m})$ & $\boldsymbol{h}_{\text {emax }}(\boldsymbol{\mu m})$ & $\boldsymbol{h}_{\text {fmax }}(\boldsymbol{\mu m})$ & $\boldsymbol{l}_{\text {emax }}(\boldsymbol{\mu m})$ & $\boldsymbol{l}_{\text {fmax }}(\boldsymbol{\mu m})$ \\
\hline \hline 92 & 1.087 & 0.870 & 0.300 & 0.303 \\
\hline 110 & 1.032 & 3.571 & 0.2998 & 0.600 \\
\hline
\end{tabular}

\section{DEFORMATION AND DISTRIBUTION CHARAC- TERI-STICS OF RESIDUAL UNITS OF MACHINED SURFACE}

According to the tool-workpiece contact relationship and the cutting motion trajectory equation, the formation conditions of machined surface are determined. Through the solution of cutting layer parameters of contact points among adjacent teeth in the forming process of milled surface, the residual units of machined surface are constructed, as shown in Fig. (8).

In the Fig. (8), le1 and le2 are the residual unit lengths along row spacing, lf1 and lf 2 are residual unit lengths along feed direction, hmax is the maximum height of residual unit, helis the residual unit height along row spacing on the highest point profile along row direction, he 2 is the residual unit height on the lowest point profile along row direction, $\mathrm{hfl}$ is the residual unit height on the highest point profile along feed direction, and $\mathrm{hf} 2$ is the residual unit height on the lowest point profile along feed direction.

With cutting parameters and vibration data from Table 2, by adopting Eq. 4 and the above model measure methods conduct the characteristic parameters analysis of residual unit of machined surface with overhanging volume of $92 \mathrm{~mm}$ and $110 \mathrm{~mm}$ as shown in Table 3 .

In Table 3,1 is the overhanging volume of milling cutter, hemax is the maximum height of residual units along the row direction, hfmax is the maximum height of residual units along the feed direction, lemax is the maximum length of residual units along the row direction, lfmax is the maximum length of residual units along the feed direction.
As shown in Table 3, the analysis results show that under the same conditions of cutting parameters, vibration and overhanging volume make the residual units of machined surface generate different degree deformations. The model of extracting residual units of machined surface can reflect the vibration and the overhanging volume affect the milled surface topography.

Using the above method continuously solves the residual unit along the cutting motion trajectory and obtains the distribution characteristics of residual units of machined surface.

$$
\begin{aligned}
& \Delta h_{\max }=\max \left(\left|h_{\text {emax }}-h_{f \max }\right|\right), \Delta l=l_{\text {max }}-l_{\text {min }} \\
& \cos \left(\phi_{w}\right)=\frac{\vec{n}_{f} \cdot \vec{n}_{w}}{\left|\vec{n}_{f}\right|\left|\vec{n}_{w}\right|}
\end{aligned}
$$

Where $\Delta h_{\max }$ is the distribution degree of residual unit on the machined surface along the normal direction. $\Delta l$ is the change degree of residual unit on the machined surface along the feed direction and the row ledge. $l_{\max }$ is the maximum length of residual unit. $l_{\min }$ is the minimum length of residual unit. $\boldsymbol{n}_{f}$ is the unit vector along the feed direction. $\boldsymbol{n}_{w}$ is the unit vector along the distribution direction of residual unit. $\varphi_{w}$ is an included angle between the distribution direction of residual unit and the feed direction, which range is from $0^{\circ}$ to $90^{\circ}$.

The surface topography of high speed ball-end milling cutter is analyzed and tested by using the Eq. (5). This experiment adopts the ball-end milling cutter with the diameter of $20 \mathrm{~mm}$ and two teeth. The overhanging volume is $92 \mathrm{~mm}$, the revolving speed is $5000 \mathrm{rpm}$, the feed of each tooth is $0.3 \mathrm{~mm}$, 


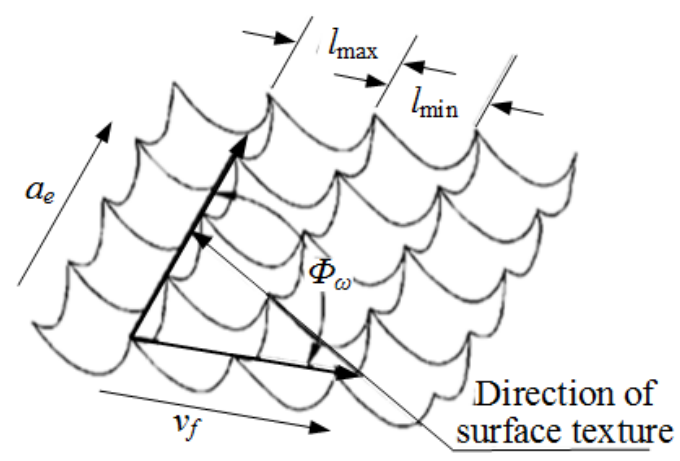

Fig. (9). Results of distribution characteristics of residual unit.

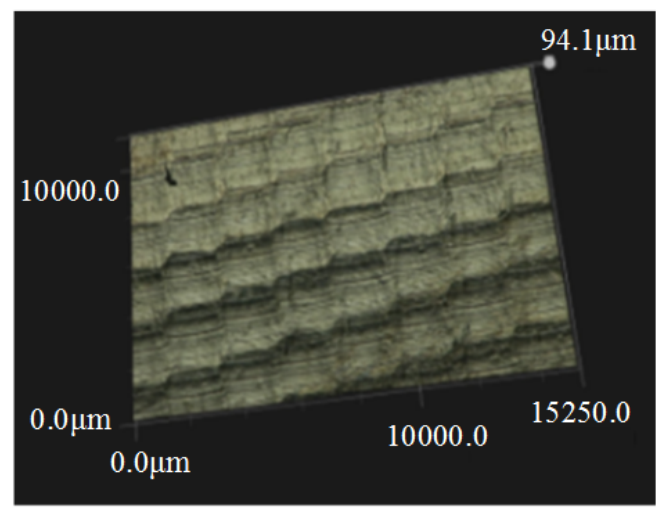

Fig. (10). Experiment result.

Table 4. Simulation and experiment results of surface topography

\begin{tabular}{|c|c|c|c|}
\hline Process Scheme & $\begin{array}{c}\text { Revolving Speed } \\
(\mathbf{r p m})\end{array}$ & $\begin{array}{c}\text { Feed Speed } \\
(\mathbf{m m} / \mathbf{m i n})\end{array}$ & $\begin{array}{c}\text { Row Spacing } \\
(\mathbf{m m})\end{array}$ \\
\hline \hline 1 & 3000 & 2400 & 0.5 \\
\hline 2 & 4000 & 3200 & 0.4 \\
\hline 3 & 5000 & 4000 & 0.3 \\
\hline 4 & 6000 & 3600 & 0.3 \\
\hline
\end{tabular}

the row spacing is $0.3 \mathrm{~mm}$, the cutting depth is $0.2 \mathrm{~mm}$ and the machining inclination angle is $15^{\circ}$. The material of specimen is hardened steel $\mathrm{Cr} 12 \mathrm{MoV}$, the hardness is HRC55 60. The distribution characteristics of residual unit of machined surface are shown in Fig. (9) and Fig. (10). The analysis and experiment results show the cutting motion trajectory difference exists between two adjacent teeth under the vibration, which the length and the height of residual unit have changed and the distribution on the machined surface obviously appears directivity, thereby causing significant texture characteristic for the milled surface topography.

\section{MILLING SURFACE TOPOGRAPHY SIMULATION AND VERITY EXPERIMENT OF HIGH SPEED MILLING OF HARDENED STEEL}

In order to keep cutting efficiency during $1000 \mathrm{~mm} 3$ / $\min \sim 1200 \mathrm{~mm} 3 / \mathrm{min}$, adopting an integrated scheme with different revolving speed, feed speed and row spacing, the cutting experiment was conducted with high speed ball-end milling cutter to cut hardened steel and extract milling cutter vibration data. The ball-end milling cutter has the diameter of $20 \mathrm{~mm}$ and two teeth. The overhanging volume is $92 \mathrm{~mm}$, the cutting depth is $0.2 \mathrm{~mm}$ and the machining inclination angle is $15^{\circ}$. The material of specimen is hardened steel Cr12MoV.

According to the experimental results of milling cutter vibration, the residual unit of machined surface model for cutting hardened steel with high speed ball-end cutter is contracted by the modifying model of cutting motion trajectory, for which analysis method is used to simulate the milled surface topography of hardened steel. Through the VHX-600 super depth field microscope, the milled surface topography is tested. The vibration data, the simulation result and the experiment results are shown in Table 4 and Fig. (11) Fig. (14). 


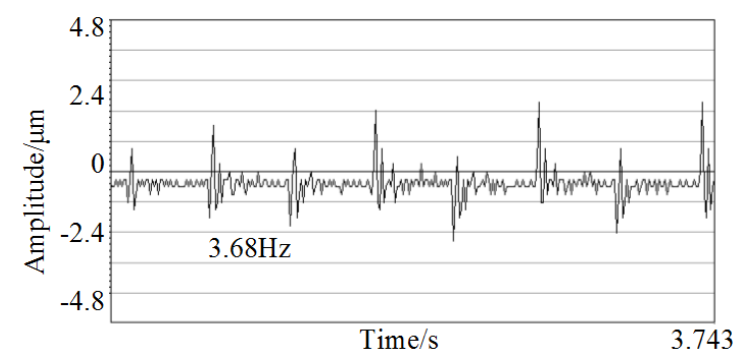

(a) Cutter vibration data

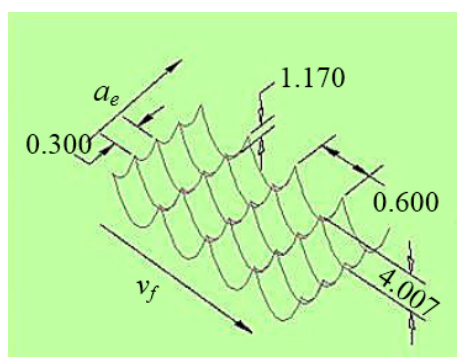

(b) Simulation of milled surface topography

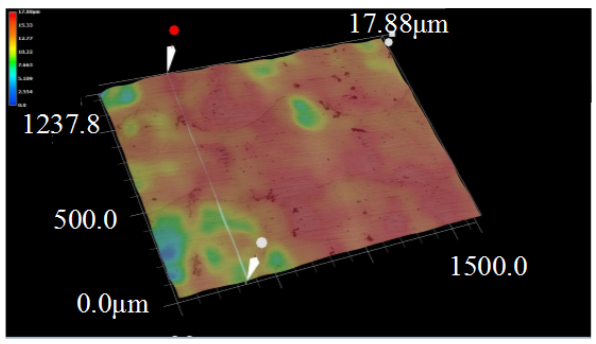

(c) Experimental result

Fig. (11). Experiment scheme 1.
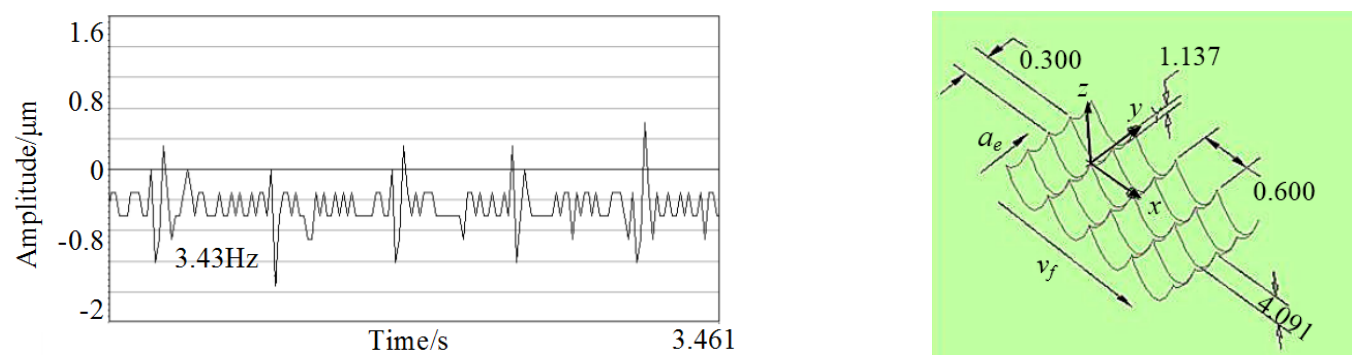

(a) Cutter vibration data

(b) Simulation of milled surface topography

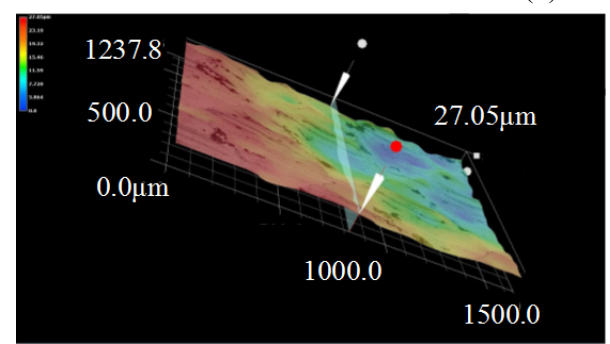

(c) Experimental result

Fig. (12). Experiment scheme 2. 


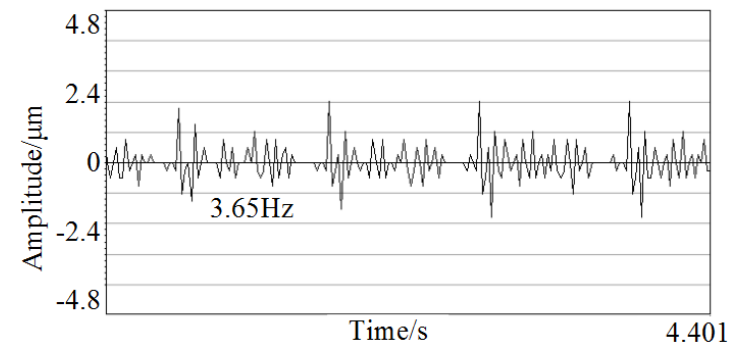

(a) Cutter vibration data

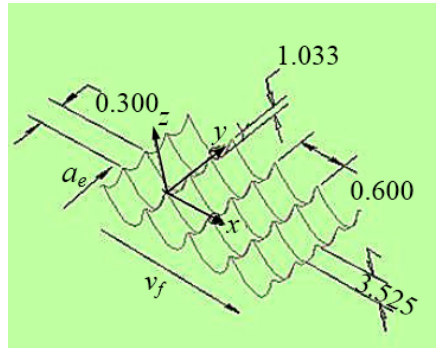

(b) Simulation of milled surface topography

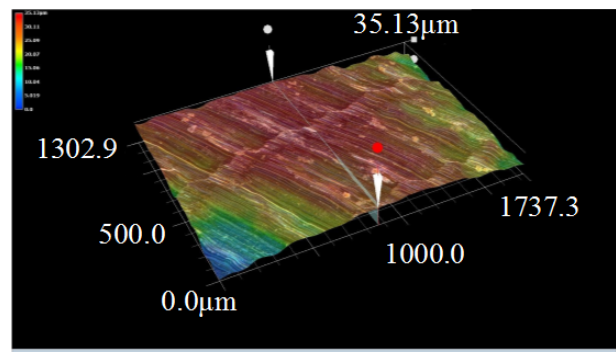

(c) Experimental result

Fig. (13). Experiment scheme 3.

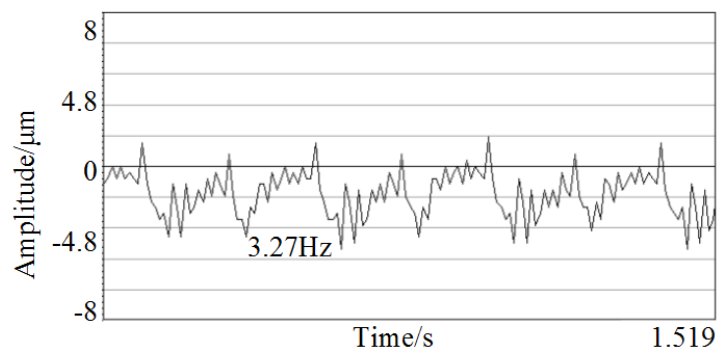

(a) Cutter vibration data

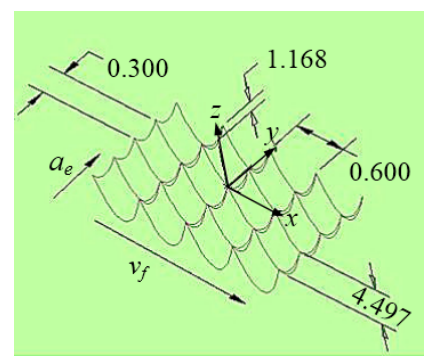

(b) Simulation of milled surface topography

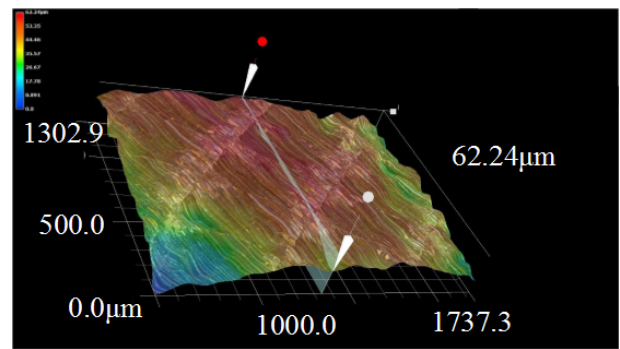

(c) Experimental result

Fig. (14). Experiment scheme 4.

Based on the formulation results, we evaluated the above process schemes through the residual unit height of milled surface topography and the uniformity coefficient of unit distribution. The process scheme order which conforms to requirements of the cutting efficiency and machined surface quality is scheme 3 , scheme 2 , scheme 1 and scheme 4 . Those are the same for the experiment test results of the cutting efficiency and the milled surface topography. The model analysis method of milled surface topography can effectively solve a restrictive problem between the machining efficiency and the machined surface quality.

\section{CONCLUSION}

With two different schemes of cutting hardened steel, the experimental results reflect a restrictive relation between the machining efficiency and the machined surface quality under the vibration. When the overhanging volume is over $100 \mathrm{~mm}$, the milled surface topography obviously changes with the high frequency vibration.

The installation errors of the blade and the tool vibration change the position relation among the workpiece, the tool and the machine system which leads to the contact point 
offset. The cutting motion trajectory model is constructed and modified by using the displacement increment of tool coordinate origin, which reflects the influence characteristics that the vibration, the installation error of blade and the overhanging volume affect the formation condition of machined surface.

Based on the deformation and distribution characteristics of residual unit of machined surface along the cutting motion trajectory, the model of residual unit of machined surface is established to reveal milled surface topography of hardened steel with high speed ball-end milling cutter under the vibration.

The cutting hardened steel experiment and milled surface simulation with high speed ball-head milling cutter show that the model analysis method of milled surface topography evaluates the process scheme order, which is in accordance with the test results of milled surface topography. The analysis method of milled surface topography can effectively solve the contradiction between the machining efficiency and the machined surface quality during cutting hardened steel with high speed milling cutter and its validity is verified.

\section{CONFLICT OF INTEREST}

The authors confirm that this article content has no conflict of interest.

\section{ACKNOWLEDGEMENTS}

This work was supported by National Natural Science Foundation of China (51375124).

\section{REFERENCES}

C. Vila, J.V. Abellan-Nebot, and H.R. Siller-Carrillo, "Study of different cutting strategies for sustainable machining of hardened steels", Procedia Engineering, vol. 132, pp. 1120-1127, 2015.
[2] W. Grzesik, J. Rech and K. Zak, "Characterization of surface textures generated on hardened steel parts in high-precision machining operations", The International Journal of Advanced Manufacturing Technology, vol. 78, pp. 9-12, 2015.

[3] C.K. Toh, "Vibration analysis high speed rough and finish milling hardened steel", Journal of Sound and Vibration, vol. 278, no. 1-2, pp. 101-115, 2004.

[4] Z.B. Liu, X.B. Wang and Z.P. Fang, "Principal composition analysis the characteristic parameter of vibration signal in micromilling process", Nanotechnology and Precision Engineering, vol. 8, no. 3, pp. 269-274, 2010.

[5] K. Tatar and P. Gren, "Measurement of milling tool vibrations during cutting using laser vibrometry", International Journal of Machine Tools and Manufacture, vol. 48, no. 3-4, pp. 380-387, 2008.

[6] D.A. Axinte, and R.C. Dewes, "Surface integrity of hot work tool after high speed milling experimental data and empirical models", Journal of Materials Processing Technology, vol. 5, pp. 325-335, 2002.

[7] P. Koshy, R.C. Dewes, and D.K. Aspinwall, "High speed end milling of hardened AISI D2 tool steel (58HRC)", Journal of Materials Processing Technology, vol. 4, pp. 266-273, 2002.

[8] N. Amin, A.U. Patwari, M.S. Sharulhazrin, and I. Hafizuddin. "Investigation of effect of chatter amplitude on surface roughness during end milling of medium carbon steel", Proceedings of the 2010 International Conference on Industrial Engineering and Operations Management, pp. 126-131, 2010.

[9] E. Aslan, "Experimental investigation of cutting tool performance in high speed cutting of hardened X210 Cr12 cold-work tool steel (62HRC)", Material and Design, vol. 26, pp. 21-27, 2005.

[10] X. Chen, J.F. Xu, Q.M. Xiao, "Cutting performance and wear characteristics of $\mathrm{Ti}(\mathrm{C}, \mathrm{N})$-based cermet tool in machining hardened steel", International Journal of Refractory Metals and Hard Materials, vol. 52, pp. 143-150, 2015.

[11] J.P. Song, C.Z. Huang, M. Lv, B. Zou, H.L. Liu and J. Wang, "Cutting performance and failure mechanisms of TiB2-based ceramic cutting tools in machining hardened Cr12MoV mold steel", The International Journal of Advanced Manufacturing Technology, vol. 70, pp. 1-4, 2014. 